\title{
Image Case: Diverticulosis of the Sigmoid Colon in a 63 Years Old Male
}

\author{
Tarik Zaher \\ Tropical Medicine Department, Faculty of Medicine, Zagazig University, Egypt
}

In this case a 63 years old Egyptian male presented by lower left abdominal pain and was diagnosed by CT as having diverticulosis of the sigmoid colon. Colonoscopy confirmed the diagnosis and excluded malignancy .

Colonic-diverticulosis in middle eastern population was found in a study done by Azzam et al., to have a low prevalence, be predominantly left-sided and associated with adenomatouspolyps. Age, hypertension and rectal bleeding predict the presence of diverticular disease[1].

Acute diverticulitis occurs in 10-25\% of patients with diverticulosis. Nowadays, elective or emergency resection is generally recommended as therapy of first choice. However, contrary concepts with merely conservative treatment or drainage - even for perforated diverticulitis - are emerging. Colonoscopy is advised 6 weeks after an attack of acute diverticulitis in order to completely evaluate the colon lumen and exclude a potential malignancy.[2,3].
Diverticular bleeding occurs due to rupture of a vas rectum at the fundus of the diverticulum. Conservative and endoscopic management is the first line and surgical resection plays a role as salvage-strategy in case of recurrent and lifethreatening bleeding. Localising the bleeding, i.e., with angiography, is crucial prior to surgery [3].

\section{References:}

1. Azzam N, Aljebreen AM, Alharbi O, Almadi MA. Prevalence and clinical features of colonic diverticulosis in a Middle Eastern population. World $J$ Gastrointest Endosc. 2013 Aug 16;5(8):391-7

2. Bar-Meir S, Lahat A, Melzer E. Role of endoscopy in patients with diverticular disease.Dig Dis. 2012;30(1):60-3.

3.von Rahden BH, Germer CT. Colonic diverticulosis and its complications: pathogenesis, classification and clinical implications. Zentralbl Chir. 2013 ;138 Suppl 2:e81-5.

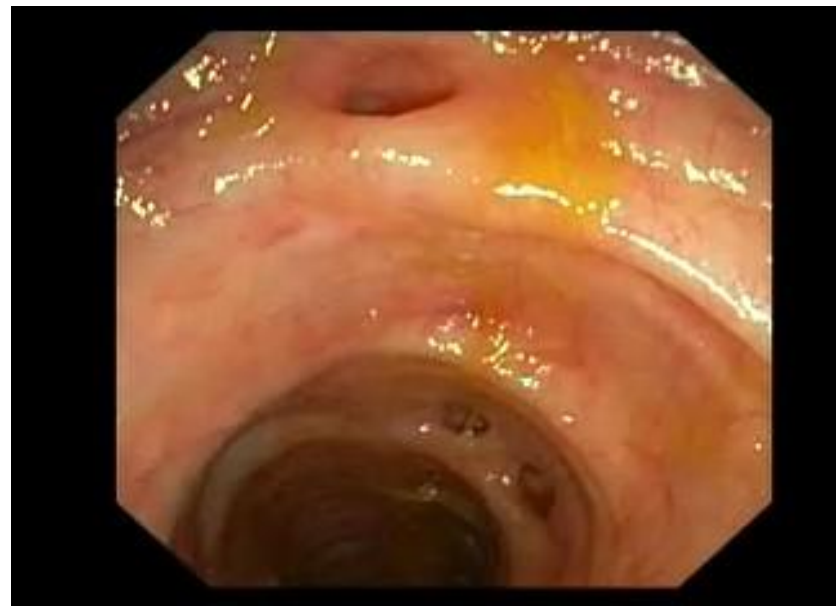

Figure 1: Diverticula of the sigmoid colon 